\title{
INVESTIGATING THE DRAG COEFFICIENT OF SCALED MODEL CAR BY USING WIND TUNNEL
}

\author{
Sumit Krishnan ${ }^{1}$, Murtaza $\mathrm{Ma}^{2}$, Vishal Kesari ${ }^{3}$ \\ ${ }^{1}$ Assistant Professor, Amity University (Lucknow Campus) India \\ ${ }^{2}$ Professor, Amity University (Lucknow Campus) India, \\ ${ }^{3}$ Assistant Professor, Institute of Engineering and Technology Lucknow UP India
}

\begin{abstract}
This paper reviews use of scale modelling in automobile performance evaluation. A scale model has been used to experimentally evaluate the automobile aerodynamics in a wind tunnel. Three cases have been considered, they are model without polish, model with polish and model with add-on, a load on the roof. Drag coefficients in all the cases have been computed and compared. Empirical relations can be used to predict drag coefficients on other than test speeds.
\end{abstract}

Keywords: Scale Model, Automobile Aerodynamics, Drag Coefficient, Wind Tunnel, Car, Add-On

\section{INTRODUCTION}

A fuel efficient vehicle is needed to conserve fuel and reduce environmental pollution. Fuel efficient means less wastage of power that is efficient power pack and less power consumption in air-conditioning and navigation system. In operation of an automobile, major portion of engine's power is wasted in overcoming rolling resistance and aerodynamic drag.

The aerodynamic drag exceeds fifty percent of the total resistance to motion at speeds above $70 \mathrm{Km} / \mathrm{h}$. It is the most important factor, responsible for resistance to motion, for speeds above $100 \mathrm{Km} / \mathrm{h}$. Automobile body designers have understood its importance and a large number of efforts have been made $[1,2,3]$. They have tried to stream line vehicle body and use drag reduction add-on devices also. These efforts include studies based on scale modelling and computer simulation approaches.

A scale model [4] is most generally a physical representation of an object, which maintains all important aspects, for example material properties so that the interaction with outside world is reliable. Only then these studies will help in improving the performance.

Scale models have been used in the study and design of automobiles for aerodynamic drag and interior noise.

\section{LITERATURE REVIEW}

Krylov et al (5) used reduced-scale simplified models of road vehicles for research into vehicle interior noise to predict structure-borne interior noise in real vehicles.

Choudhry et al (7) used a 1/10th scale model of a semitrailer truck and studied the aerodynamic impact of various fuel saving devices used in a commercial vehicle. Drag reduction up to $26 \%$ is possible by full-skirting (using the front fairing, side skirting and gap filling) of the tractor and the semi-trailer unit.
Sultika and Nozick (8) used a scaled (1:15) model of semitrailer unit to optimise the design. Rear-end tapering resulted reduction in base-drag.

Alam et al (9) used a 25\% Scale Model of an Australian passenger car. Vehicle add-ons can generate 5 to $30 \%$ more aerodynamic drag depending on yaw angles. It also deteriorates the vehicle directional stability and safety of the vehicle.

Rohatgi et al (10) used a small scale model (length 1710 $\mathrm{mm}$ ) of General Motor SUV t and tested in the wind tunnel. Drag reduction of $26 \%$ and $6.5 \%$ was obtained by rear fairing and rear screen respectively. Vortex generators were also tested. Aesthetics and practical considerations can effect implementation of these options.

\section{PRESENT WORK}

In the present work, a wooden scale model (length $390 \mathrm{~mm}$ ) of a popular passenger car 'Honda City' was used (Figure 1). Wind tunnel of Amity University (Lucknow Campus) UP India (Figure 2 ) was used for these studies. Effect of add-on and surface finish on aerodynamic drag was analyzed. Measurements included manometer readings and drag force. Air velocity was calculated from pressure drop.

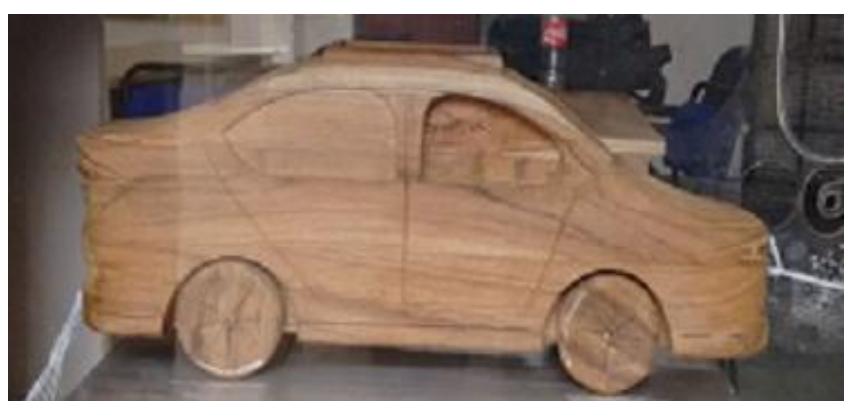

Figure 1: Scale car model (length $390 \mathrm{~mm}$ ) 


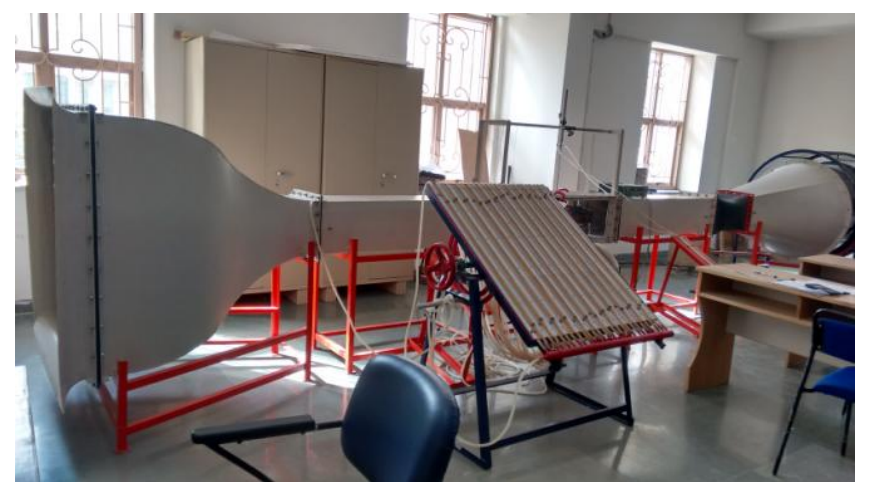

Figure 2: Wind tunnel set up with multitube manometer

Car model (Figure 3) was placed on the rectangular plate which is a stand and tightly attached on the four rod in the test section. Two hooks are fitted in the front and rear of a car model to keep it in position with strong thread. Rear thread is again tied with rear rod loosely for safety, so that it would not go into fan section. Front threads are tied to measuring device, which is fastened to a frame rod tightly for measuring drag force.

Stream Velocity, v, was calculated from pressure drop in the inclined manometer readings [6].

$=\sqrt{2 g * \Delta h * \sin \theta * \frac{\rho(\text { water })}{\rho(\text { air })}}$

Where, $\Delta \mathrm{h}$ is the difference in the columns of inclined manometer. $\theta$ is the inclination of manometer and $\rho$ is the density.

Drag Coefficient is obtained from the following relation [6].

$$
C_{\mathrm{d}}=\frac{2 \mathrm{~F}}{\rho \mathrm{v}^{2} \mathrm{~A}}
$$

Where $\mathrm{F}$ is the total drag force and $\mathrm{A}$ is the reference area.

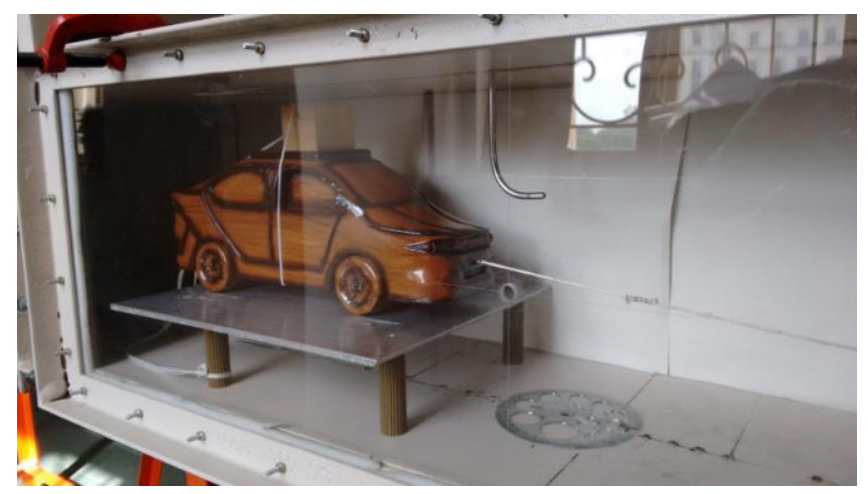

Figure 3: Car model on rectangular plate inside wind tunnel Following table 1, gives the velocity, drag force, projected area and drag coefficient for the cases considered for this study.
Table 1: Wind Tunnel Tests

\begin{tabular}{|l|l|l|l|l|}
\hline Model & $\mathrm{v} \mathrm{m} / \mathrm{s}$ & $\mathrm{a} \mathrm{m} \mathrm{sq}$ & $\mathrm{drag} \mathrm{N}$ & $\mathrm{Cd}$ \\
\hline \multirow{5}{*}{ Before polish } & 27.12 & 0.012 & 7.286 & 1.361584 \\
\cline { 2 - 5 } & 25.57 & 0.012 & 6.119 & 1.312851 \\
\cline { 2 - 5 } & 23.57 & 0.012 & 4.551 & 1.103646 \\
\hline \multirow{5}{*}{ with polish } & 27.12 & 0.012 & 7.108 & 1.270109 \\
\hline & 25.57 & 0.012 & 3.941 & 0.916912 \\
\cline { 2 - 5 } & 23.57 & 0.012 & 3.571 & 0.809341 \\
\cline { 2 - 5 } & 27.12 & 0.015 & 10.382 & 1.593146 \\
\cline { 2 - 5 } With add-on & 25.57 & 0.015 & 9.46 & 1.625435 \\
\cline { 2 - 5 } & 23.57 & 0.015 & 6.511 & 1.373426 \\
\hline
\end{tabular}

\section{RESULTS AND DISCUSSIONS}

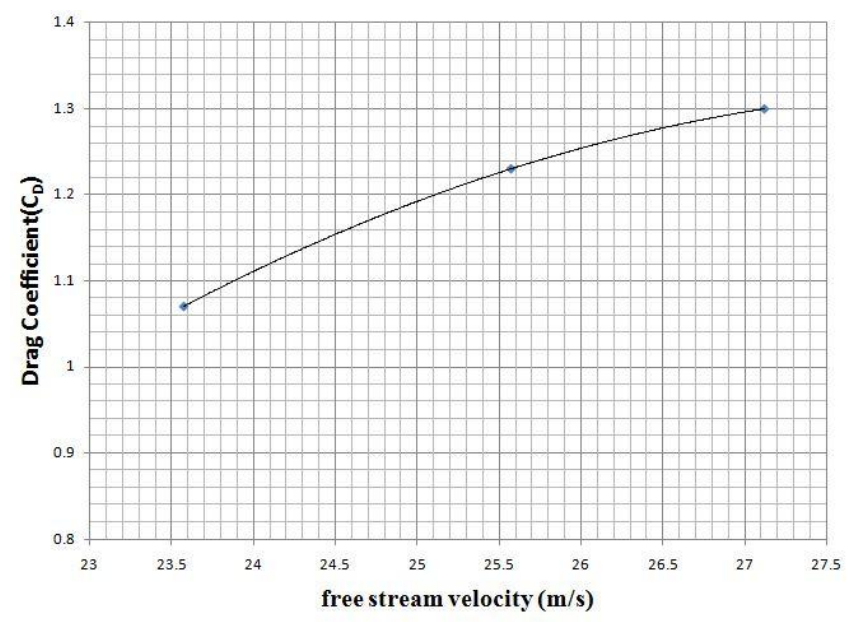

Figure 4: $C_{D}$ Vs Stream Velocity for the model without polish

Figure 4 shows variation of drag coefficient with stream velocity in case of car scale model without polish.

Drag coefficient increases with speed. It varies from 1.1 to 1.36 with the variation of stream velocity from $23.57 \mathrm{~m} / \mathrm{s}$ to $27.12 \mathrm{~m} / \mathrm{s}$.

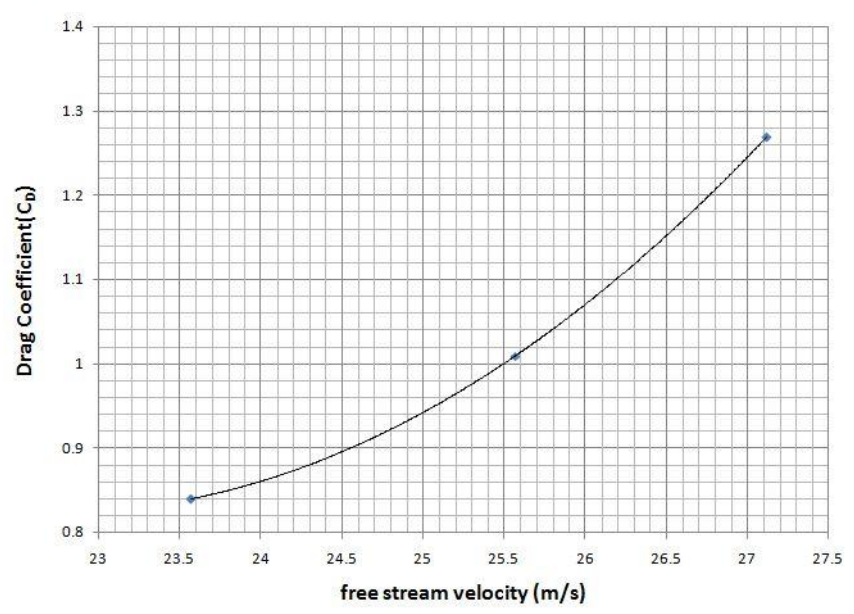

Figure 5: Drag Coefficient Vs Stream Velocity for the model with polish 
Figure 5, shows the variation of drag coefficient with velocity in case of polished surface of model. Drag coefficient varies from 0.8 to 1.27 for the same velocity range. There is reduction in drag of the order $27 \%$ at 23.57 $\mathrm{m} / \mathrm{s}$ and $6 \%$ at $27.12 \mathrm{~m} / \mathrm{s}$.

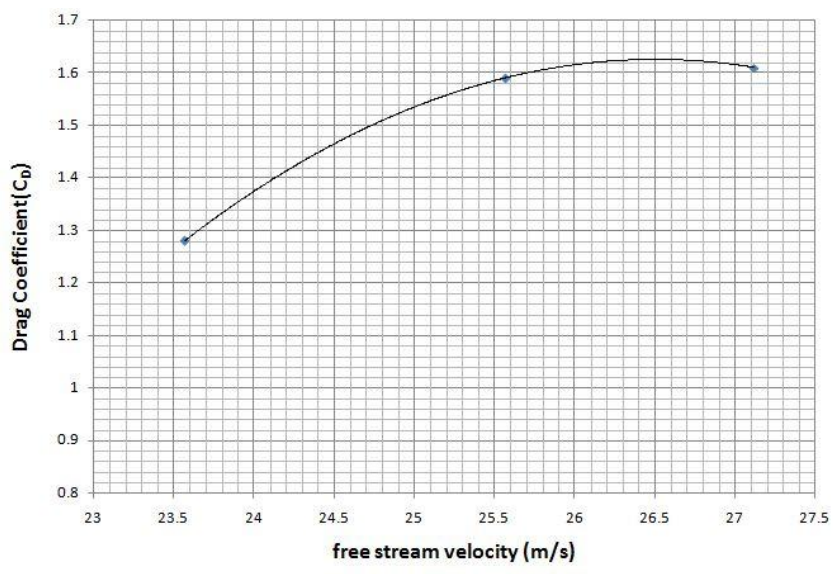

Figure 6: Drag coefficient Vs Stream Velocity for the polished model with load on roof

Figure 6, shows the variation of drag coefficient with stream velocity with polished model loaded on the roof. There is a increase in projected area from $0.012 \mathrm{~m}^{2}$ to $0.015 \mathrm{~m}^{2}$. The drag coefficient varies from 1.28 at stream velocity of 23.57 $\mathrm{m} / \mathrm{s}$ to 1.61 at stream velocity of $27.12 \mathrm{~m} / \mathrm{s}$. Because of this load, there is an increase in drag coefficient i.e. $52 \%$ at 23.57 to $26.7 \%$ at $27.12 \mathrm{~m} / \mathrm{s}$.

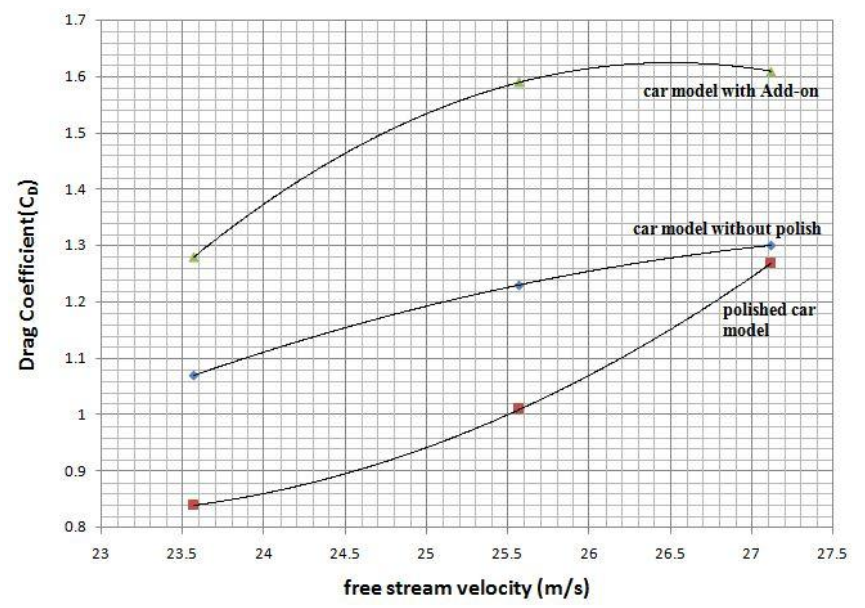

Figure 7: Comparative variation of drag coefficient for all the three cases
Figure 7, shows the comparative variation of drag coefficients in cases of model without polish, with polish and load on the roof.

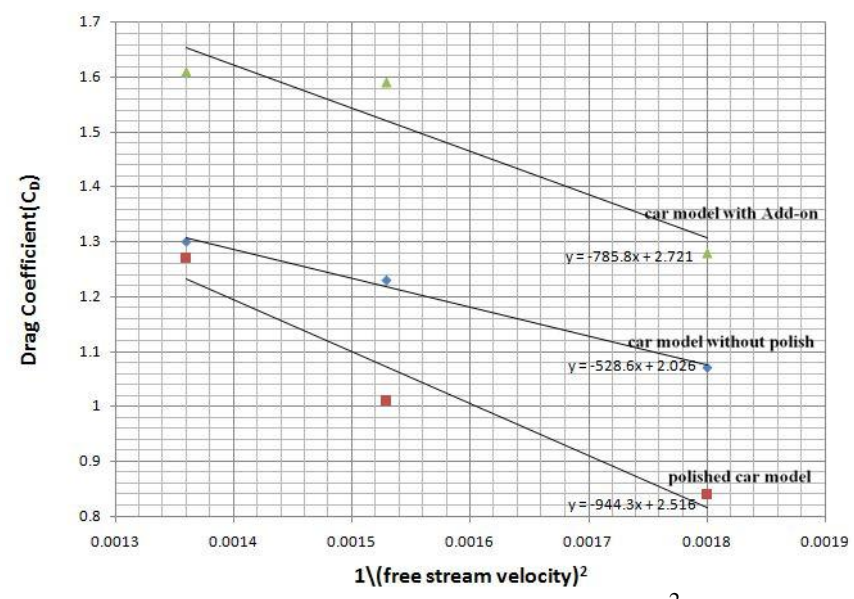

Figure 8: Drag coefficient vs $1 / v^{2}$

Figure 8 , shows the variation of drag coefficient with $1 / v^{2}$ in all the three cases and from these following lines of best fit are obtained;

$\mathrm{C}_{\mathrm{D}}$-Before polish $=2.026-528.6 / \mathrm{v}^{2}$

$\mathrm{C}_{\mathrm{D}}$-Polish $=2.516-944.3 / \mathrm{v}^{2}$

$\mathrm{C}_{\mathrm{D}}$-With add-on $=2.721-785.8 / \mathrm{v}^{2}$

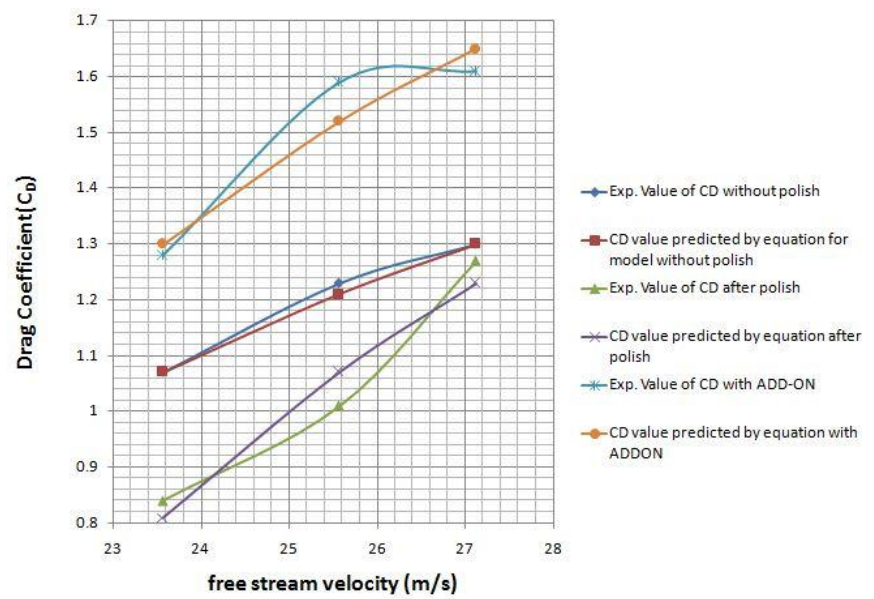

Figure 9 Drag coefficient experimental \& empirical Vs stream speed

Figure 9, shows a comparative plot of experimental and empirical values of drag coefficient vs stream velocity

Table 2: Comparison table for Experimental and Empirical values of $\mathrm{C}_{\mathrm{D}}$ for the given conditions

\begin{tabular}{|c|c|c|c|c|c|c|c|c|}
\hline \multirow[b]{2}{*}{$\begin{array}{l}\text { S. } \\
\text { No }\end{array}$} & \multirow[b]{2}{*}{$\begin{array}{l}\text { Free } \\
\text { stream } \\
\text { velocity } \\
(\mathrm{V})(\mathrm{m} / \mathrm{s})\end{array}$} & \multirow[b]{2}{*}{$\left(1 / V^{2}\right)$} & \multicolumn{2}{|c|}{ Car model without Polish } & \multicolumn{2}{|c|}{ Polished Car model } & \multicolumn{2}{|c|}{ Car model with ADD-ON } \\
\hline & & & $\begin{array}{l}\text { Experimental } \\
\text { Value of } C_{D}\end{array}$ & $\begin{array}{l}\mathrm{C}_{\mathrm{D}} \text { value } \\
\text { predicted by } \\
\text { equation } \\
\mathrm{y}=-528.6 \mathrm{x} \\
+2.026\end{array}$ & $\begin{array}{l}\text { Experimental } \\
\text { Value of } C_{D}\end{array}$ & $\begin{array}{l}\mathrm{C}_{\mathrm{D}} \text { value } \\
\text { predicted by } \\
\text { equation, } \\
\mathrm{y}=-944.3 \mathrm{x} \\
+2.516\end{array}$ & $\begin{array}{l}\text { Experimental } \\
\text { Value of } C_{D}\end{array}$ & $\begin{array}{l}\mathrm{C}_{\mathrm{D}} \text { value } \\
\text { predicted by } \\
\text { equation, } \\
\mathrm{y}=-785.8 \mathrm{x} \\
+2.721\end{array}$ \\
\hline 1. & 27.12 & 0.00136 & 1.30 & 1.30 & 1.27 & 1.23 & 1.61 & 1.65 \\
\hline 2. & 25.57 & 0.001529 & 1.23 & 1.21 & 1.01 & 1.07 & 1.59 & 1.52 \\
\hline 3. & 23.57 & 0.0018 & 1.07 & 1.07 & 0.84 & 0.81 & 1.28 & 1.30 \\
\hline
\end{tabular}


It is evident that variation at $27.12 \mathrm{~m} / \mathrm{s}$ is from $0 \%$ (model before polish) to $3.1 \%$ in case of polished model. Similar is the situation at $23.57 \mathrm{~m} / \mathrm{s}$. Maximum variation is at 25.57 $\mathrm{m} / \mathrm{s}$, which is from $1.6 \%$ to $4.4 \%$.

\section{CONCLUSIONS}

Wind tunnel tests have been conducted for a scale model (length $390 \mathrm{~mm}$ ) of a passenger car without polish, with polish and with an add-on on the roof. The stream velocities for these tests were 23.57, 25.57 and $27.12 \mathrm{~m} / \mathrm{s}$. Following conclusions are made from these tests;

1. Drag coefficient increases with speed. Drag coefficient was 1.36 at the maximum stream velocity of 27.12 in case of scale model without polish.

2. There is a reduction in drag coefficient from 1.36 to 1.27 due to polishing of scale model at maximum stream velocity of $27.12 \mathrm{~m} / \mathrm{s}$. Therefore it is concluded that the drag reduction is possible by improvement in surface finish.

3. Aerodynamics drag for scale model of a car body is 1.27 (without Add-on) and 1.59 (with Add-on) at a maximum velocity $(27.12 \mathrm{~m} / \mathrm{s})$.

4. Empirical relations can be used for quick prediction of drag coefficient at different stream velocities.

There is a need to study the effects on pitching moment coefficient associated with a car and validating the same through CFD approaches for automobile design optimisations.

\section{ACKNOWLEDGEMENTS}

We thank Brig. (Retd.) U K Chopra, Wg. Cdr. (Retd.) Anil Kumar, Dr. A.K. Jouhari, Prof P.C. Gupta, Prof Vivek Verma and Prof V. Saxena for encouragements. Our thanks are also to Mr. Ravindra Singh lab incharge for assistance in conducting the lab experiments.

\section{REFERENCES:}

[1]. "Research on Aerodynamic Drag Reduction by Vortex Generators". Masaru Koike, Tsunehisa Nagayoshi, Naoki Hamamoto, Mitsubishi Motors/ Technical Review, 2004. No 6, pp.1

[2]. S.P.Zagorodnikov - "Modeling of road in wind tunnel tests» - News of higher education institute. Machine building. -1980 .

[3]. 'The Study of Road Vehicle Aerodynamics Using Wind Tunnel Models', Carr G.W., Paper 14, Proc. 1st Symp. Road Vehicle Aerodynamics, London, 1969.

[4]. http://en.wikipedia.org/wiki/Scale_model

[5]. 'Recent progress in reduced-scale modelling of vehicle interior noise', V.V. Krylov, V.B. Georgiev and R. Gorman, e-mail: V.V.Krylov@lboro.ac.uk

[6]. Effect of Add-on and Surface Finish on Aerodynamic Drag of a Passenger Car " Kesari V \& Murtaza MA, International Journal of Automobile Engineering Research and Development, pp 1-18, Vol - 5, Issue - 2; Edition: Aug 2015 "
[7]. 'A study on aerodynamic drag of a semi-trailer truck', Harun Chowdhury, Hazim Moria, Abdulkadir Ali, Iftekhar Khan, Firoz Alam and Simon Watkins School of Aerospace, Mechanical and Manufacturing Engineering, RMIT University, Melbourne, VIC 3083, Australia.

[8]. 'Aerodynamic Devices to Reduce the Base and Underbody Drag of Semitrailer Unit', Matěj Sulitka, Ing., sulitka@fs.cvut.cz, Jiří Nožička, Prof., Ing., Ph.D., Czech Technical University in Prague, Institute of Fluid Dynamics and Power Engineering, Division of Fluid Dynamics and Thermodynamics, Technická 4, 16607 Praha 6, Czech Republic; jiri.nozicka@fs.cvut.cz

[9]. 'Effects of Vehicle Add-Ons on Aerodynamic Performance', Firoz Alam, Harun Chowdhury, Hazim Moria and Simon Watkins, School of Aerospace, Mechanical and Manufacturing Engineering, RMIT University, Melbourne, Australia Proceedings of the 13th Asian Congress of Fluid Mechanics 17-21 December 2010, Dhaka, Bangladesh.

[10]. Methods of Reducing Vehicle Aerodynamic Drag, Upendra S. Rohatgi, Presented at the ASME 2012 Summer Heat Transfer Conference, Puerto Rico, USA July 8-12, 201 